\title{
PHENOTYPIC SELECTION IN LEPANTHES RUPESTRIS STIMSON
}

\author{
Sol Taína Cintrón Berdecía \& Raymond L. Tremblay ${ }^{1}$ \\ University of Puerto Rico at Humacao Potal station CUH, Department of Biology \\ 100 carr. 908, Humacao, Puerto Rico 00791 \\ ${ }^{1}$ Author for correspondence: raymond@hpcf.upr.edu
}

Natural selection is defined as a process in which a population has: variation among individuals, a strong relationship between a character and reproductive success (fitness differences) and character heritability (Endler 1986). Phenotypic selection on the phenotypes was estimated using regression techniques and expressed as the selection coefficients (Arnold \& Lande 1983). We assume that character differences and phenotypic selection is heritable. The coefficients provide an estimate of direct selection and indirect selection acting through correlated characters, the linear (directional) or non-linear (disrupted and stabilizing) analysis and can be expressed in standard deviations units which can be compared within species and populations (O’Connell \& Johnston 1998). The genus Lepanthes Sw. is an epiphytic or lithophyte taxon often limited to very small patchily distributed populations (Tremblay 1997a). This genus is distributed from the south of Mexico and the Antilles through the Andes and Bolivia, where a large proportions of the species are local endemics and distributed within very small geographical areas.

Lepanthes rupestris is a common lithophyte along rivers of the northwestern slopes of the Luquillo Mountains (Tremblay 1997). Plants have a thin stem, segmented lepanthiform sheaths and a solitary, heart-shaped leaf that bears one or two $5 \mathrm{~mm}$ flowers at a time in a sequential inflorescence. The sepa1s are yellow and the petals creamy yellow with two thin, vertical, crimson stripes at the margins (Morales 1977). The middle lobe of the lip is distinct, short, blunt, pubescent, and seems forked when looked at from the side (Stimson 1969).

Seven populations were sampled from two river basins, Quebrada Sonadora and Quebrada Grande in the Caribbean National Forest. All populations were visited monthly beginning in July or August 1994 except population one which began in March 1993, all sampling ended in January 1996. Consequently the seven populations were sampled for $34,19,18$, 19, 19, 19, and 18 months, respectively. Flowers were preserved in a solution of $70 \%$ ethanol, $37 \%$ formalin and propionic acid in a 90: 5: 5 ratio and morphological characters were measured with Olympus dissecting microscope fitted with a $0.1 \mathrm{~mm}$ micrometer. To measure phenotypic selection, we measured female and male fitness through the production of the total fruit and pollinia removed of each plant of the seven populations.

Twelve morphological traits were measured on 220 individuals to determinate the morphological variance among individuals; these include length of the column, flower size, width of sepal dorsal, length and width of posterior petal lobe, length and width of anterior petal lobe, length and width of front lip, lip mid lobe length, anther cap opening and the distance between sepals.

To estimate the total strength of selection on a character, indirectly and directly through correlated characters we used coefficients from univariate regression (one character). When expressed in units of standard deviation, univariate regression coefficients are equivalent to selection differentials (Lande \& Arnold 1983). Directional ( $\left.\beta^{\prime}\right)$ and nonlinear $\left(\gamma^{\prime}\right)$ selection differentials and gradients were estimated using the following regression model:

$$
w=a+\sum_{i=1}^{n} \beta_{j}^{r}+\frac{1}{2} \sum_{i=1}^{n} \gamma_{j}^{r} \hat{z}_{i}+\sum_{i=1}^{n} \sum_{j>1}^{r} \gamma_{i}^{\prime} z_{i}^{r} z_{j}^{\prime}+\varepsilon
$$

where $w$ is the relative standardized fitness measure, $\alpha$ is a constant, $z$ ' is the standardize trait value, and $\varepsilon$ is error. Directional differentials and gradients 
were obtained using the first two terms on the right side of the equation, whereas nonlinear coefficients where obtained using the full model (Lande \& Arnold 1983). Previous to the regression analysis every absolute female and male success was divide by the population average to calculate the standardized fitness, w, (O’Connell \& Johnston 1998). Traits values before selection were standardized to zero mean and unit standard deviation. These values were squared and entered into the regression model, yielding. All regression coefficients were expressed in units of change in relative fitness per standard deviation, as indicated by the prime symbol, thus facilitating comparison of the selection among traits and between the populations (Lande \& Arnold 1983).

In percent term distribution of reproductive success in all populations the individuals are distributed along the extreme intervals (Table 1). We obtained $13.2 \%$ of the individuals with zero pollinia removed and zero fruit produced and a substantial amount of the individuals had a high male (4+) and female fitness $(3+)$ of $17.3 \%$.

Morphological variation is significantly different among measured characters. The largest amount of variation among characters is observed in anther cap opening, lip mid lobe length, distance between sepals, front lip width and width of anterior petal lobe.

Phenotypic selection. Fitness based on female and male reproductive success suggests that the length of the column had a positive directional coefficient with $r^{2}=4 \%, p=0.004$ and $r^{2}=3 \%, p=0.015$

Table 1. Distribution of male and female fitness in Lepanthes rupestris as percentage of the total observations (number of plants).

\begin{tabular}{c|l|l|c|c|c}
\hline $\begin{array}{c}\text { Male } \\
\text { Fitness }\end{array}$ & \multicolumn{5}{c|}{$\begin{array}{c}\text { Female } \\
\text { Fitness }\end{array}$} \\
\hline & 0 & 1 & 2 & $3+$ & Total \\
\hline 0 & $13.2(29)$ & $3.6(8)$ & $0.9(2)$ & $1.4(3)$ & 19.1 \\
\hline 1 & $9.1(20)$ & $10(4.5)$ & $3.2(7)$ & $2.3(5)$ & 19.1 \\
\hline 2 & $6.4(14)$ & $4.1(9)$ & $1.4(3)$ & $6.0(13)$ & 17.7 \\
\hline 3 & $5.4(12)$ & $2.3(5)$ & $3.6(8)$ & $6.4(14)$ & 17.7 \\
\hline $4+$ & $3.6(8)$ & $2.3(5)$ & $3.2(7)$ & $17.3(38)$ & 26.4 \\
\hline Total & 37.7 & 16.8 & 12.3 & 33.2 & 220
\end{tabular}

respectively. Moreover the female fitness of the length of front lip had a positive directional selection coefficient with $\mathrm{r}^{2}=4 \%, \mathrm{p}=0.006$. No significant directional, disruptive and stabilizing selection was detected in any other morphological character.

Phenotypic selection in Lepanthes rupestris was absent in almost all measured characters and when observed was of low intensity. The length of the column had a positive directional phenotypic selection for female and male fitness, and the length of the front lip had evidence for positive directional selection through the female fitness variable only. This phenomenon may occur because the potential phenotypic selection could be imposed by biotic agents such as the still undescribed pollinator (Gómez 1993).

In a study of natural selection on floral traits in two species of Lobelia a positive directional selection with multivariate analysis on two floral characters was found. Those characters influence the pollen receipt proficiency of the pollinators (Johnston 1991).

We suggest that some biotic agents like pollinators influence the phenotypic selection on the length of the column and the length of front lip in L. rupestris . The most probable pollinator of Lepanthes are small dipterans, such as Drosophila (Tremblay 1997a) or fungus gnats (Blanco \& Barboza 2001).

Table 2. Mean (SD) and coefficient of variation of measured morphological characters of Lepanthes rupestris ( $\mathrm{W}=$ width, $\mathrm{L}=$ length, post $=$ posterior, ant $=$ anterior $)$.

\begin{tabular}{l|c|c|c|c}
\hline Traits & \multicolumn{4}{|c}{ Species level variation } \\
\hline & $\mathrm{n}$ & Mean & $\mathrm{SD}$ & $\% \mathrm{CV}$ \\
\hline L of column & 201 & 41.47 & 4.60 & 11.1 \\
Flower size & 208 & 82.37 & 8.17 & 9.9 \\
W of sepal dorsal & 189 & 34.38 & 4.62 & 13.5 \\
L post lobe petal & 187 & 46.75 & 5.60 & 12.0 \\
W post lobe petal & 188 & 30.84 & 4.35 & 14.3 \\
L ant lobe petal & 189 & 34.13 & 4.92 & 14.4 \\
W ant lobe petal & 188 & 16.76 & 3.98 & 23.7 \\
Front lip length & 186 & 46.71 & 5.49 & 11.7 \\
Front lip width & 186 & 15.95 & 3.90 & 24.5 \\
Mid lobe length & 176 & 5.87 & 2.01 & 34.2 \\
Anther cap opening & 185 & 13.56 & 5.01 & 37.0 \\
Distance b/w sepals & 184 & 58.44 & 11.85 & 20.3
\end{tabular}


Pollinator limitation may limit reproductive success in this orchid and consequently selection maybe temporal, stochastic and or local depending on the availability of the pollinator (Tremblay, Ackerman, Zimmerman \& Calvo, unpublished). Resource limitation on female reproduction (fruit and seed production) could also limit selection (Campbell 1989). However orchids are usually pollinator limited and not resource limited (Tremblay, Ackerman, Zimmerman \& Calvo, unpublished). We found a positive directional female selection for the length of the column and the front lip and we can infer that this parts of the flowers may play an important role in the pollinator-plant interaction.

An alternative factor that warrant careful though is sample size and population structure of the present experiment. For selection to be dominant in a population it must be large enough to discount the effect of genetic drift. Our present analysis includes the sum of seven populations, consequently analysis of selection on floral characters at the individual population may suggest different patterns. Selection will occur at the species or the population level depending on the amount of gene flow among populations. If gene flow among populations is low, <1 per generation, then evolution will occur at the population level, if it is larger then 2 migrants per generation, then selection will be at the multi-populational level. Present allozyme analysis of gene flow estimate in Lepanthes rupestris suggests that individual populations may be acting as individual evolutionary units (Tremblay \& Ackerman 2002, Tremblay, Ackerman, Zimmerman \& Calvo, unpublished). Consequently future work will evaluate selection at the population level.

\section{LiterATURE Cited}

Blanco, M. \& G. Barboza. 2001, Polinización en Lepanthes: un nuevo caso de pseudocopulación en las orquídeas. San José, 2do Seminario Mesoamericano de Orquideología y Conservación. Programa de Conferencias: Resúmenes. San José, 23-26 de mayo 2001. p. 13.

Campbell, D.R. 1989. Components of phenotypic selection: pollen export and flower corolla width in Ipomosis aggregata. Evolution 45: 1458 - 1467.

Endler, J.A. 1986. Natural Selection in the Wild, Princeton, USA: Princeton University Press.

Gómez, J.M. 1993. Phenotipic selection on flowering synchrony in a high mountain plant, Hormathophyla spinosa (Cruciferae), J. Ecol. 81: 605 - 613.

Johnston, M.O. 1991. Natural selection in two species of Lobelia with different pollinators. Evolution 45: $1468-$ 1479.

Lande, R. \& S.J. Arnold 1983. The measurements of selection on correlated characters, Evolution 37: 1210 -1226 .

Luer, C.A. 1996. Lepanthes subgenus of Ecuador. Icones Pleurothallidinarum 14: $1-12$.

Morales, W.R. 1977. The endemic orchid species of Puerto Rico. Amer. Orch. Soc. Bull. 46: 727 - 730.

O'Connell, L.M. \& M.O. Johnston. 1998. Male and female pollination success in a deceptive orchid, a selection study. Evolution 79: 1246 - 1260.

Stimson, W.R. 1969. A revision of Puerto Rican species Lepanthes (Orchidaceae). Brittonia 21: 332 - 345.

Tremblay, R.L. 1997a. Distribution and dispersion patterns of individuals in nine species of Lepanthes (Orchidaceae). Biotropica 29: 38 - 45.

Tremblay, R.L. 1997b. Morphological variance among populations of three tropical orchids with restricted gene flow. Plant Sp. Biol. 12: 85 - 96.

Tremblay, R.L. 2000. Plant longevity in four species of Lepanthes (Pleurothallidinae; Orchidaceae). Lindleyana 15: $257-266$.

Sol Taína Cintrón Berdecía es estudiante de Bachillerato en Biología del Programa de Manejo de Vida Silvestre en la Universidad de Puerto Rico en Humacao. Actualmente cursa su cuarto año de estudios. En agosto de 2002 comenzó su primera experiencia en investigación. Tiene como proyecto el tema de la ecología evolutiva de la orquídea Lepanthes rupestris con el Dr. Raymond Tremblay. Ella ha presentado conferencias como NCUR en Utah, el Coloquio Nacional de la Mujer y el Simposio de Fauna y Flora del Caribe en la UPR-Humacao. Aspira a lograr un doctorado en una diciplina relacionada con el manejo de vida silvestre y ser profesora de dicha diciplina en Puerto Rico. 